\title{
Using Online Tutorials in an Introductory Engineering Graphics Course to Improve Outcomes
}

\section{Dr. Nancy E. Study, Pennsylvania State University, Erie}

Dr. Nancy E. Study is on the faculty of the School of Engineering at Penn State Behrend where she teaches courses in engineering graphics and rapid prototyping, and is the coordinator of the rapid prototyping lab. Her research interests include visualization, standardization of CAD practices, and haptics. Nancy is a former chair of the ASEE Engineering Design Graphics Division and is currently the Circulation Manager and Treasurer of the Engineering Design Graphics Journal. She received her B.S. from Missouri State University, and M.S. and Ph.D. from Purdue University.

\section{Mr. Michael Lobaugh, Pennsylvania State University, Erie}

Lecturer in Engineering for 17 years. Manufacturing engineering related jobs for previous 20 years. Current teaching subjects include graphics, manufacturing, lean $\mathrm{mfg}$, mechatronics, and senior design 
Using On-line Tutorials in an Introductory Engineering Graphics Course to Improve Outcomes 


\begin{abstract}
In an introductory engineering graphics course at Penn State Behrend, CAD-specific instruction had traditionally been developed by individual instructors and whilst non-CAD course content and theory-related outcomes such as orthographic projection and hand sketching skills remained relatively consistent across course sections, the CAD abilities of students who passed the course varied. These differences caused problems with instructor expectations and student capabilities in the second course of a two-course engineering graphics series. Discussion between the course coordinator, faculty teaching the graphics courses, and the administration resulted in the implementation of PTC's Precision LMS in a partially flipped classroom environment that would require students to complete tutorials on the basic functions of the Creo software outside of lab time. Then during lab, instead of focusing on the mechanics of which buttons to click, more time was spent on demonstrations and in-class work that focused on creating effective models, implementing design intent, and using course-specific standard files and formats. Data is being collected and analyzed to assess not only the outcomes of the first engineering graphics course, but also the CAD related capabilities and knowledge of students at the point they are beginning the second course. Initial results indicate a statistically significant improvement in grades on the final CAD project in the first course when compared to semesters where the on-line instruction was not used. A pretest has been developed for implementation in the second course, consisting of questions specifically related to CAD skills and course-specific formats and standards. Results from a limited implementation indicate a majority of students earned a passing grade on the quiz.
\end{abstract}

\title{
Introduction
}

The first course in a two-course engineering graphics series at Penn State Behrend, EGT 120, includes instruction on: sketching, orthographic and isometric views, section and auxiliary views, dimensioning and dimensioning standards, working drawings, parametric modeling, design intent, and assemblies, among other topics. The software used is Creo. There is no prerequisite, and no prior knowledge of the course topics or experience with CAD software of any kind is required.

The second course, EGT 121, necessitates knowledge in the topics and theory covered in EGT 120, either by taking and passing EGT 120, or transferring its equivalent from another university. Other prerequisite knowledge includes the ability to create models, assemblies, and drawings in Creo, the implementation of Penn State Behrend course-specific standards of formatting, and the use of particular file, model, assembly, and drawing templates. Students with transfer credit for EGT 120 who have knowledge of the course content but no experience in Creo may enroll in a one-credit course in which they learn Creo basics and campus-specific standards before enrolling in EGT 121.

The instructors in EGT 121 were noticing a lack of uniformity in the Creo abilities of students coming into the course having passed, usually just the previous semester, EGT 120. Although some time was spent in class during the first week of the semester going over course expectations and doing some review, the amount of content in EGT 121 does not allow time for extended review and students who fell behind early often were unable to catch up with their better prepared classmates, even with help during the instructors' office hours and the assistance of tutors. 
All faculty teaching EGT 120 used the same syllabus and taught the same topics in the same order, but how the instruction was accomplished, especially the CAD instruction, was left up to the individual, aside from requiring students to use course-specific templates and formatting. Some faculty used self-created step-by-step tutorial handouts, others only did in-class demos without handouts, some relied primarily on YouTube videos, and these inconsistent methods did not yield reliable, acceptable outcomes. To help alleviate these inconsistencies, the course coordinator set up a meeting with the department chair and the full-time faculty who taught engineering graphics courses to discuss how to achieve consistency in CAD outcomes of EGT 120. The result of this meeting was a decision to implement the mandatory use of standard online tutorials (assuming a successful pilot test), common in-class and homework problems across all course sections, and uniform standards and rubrics for assessing CAD work.

Another result of the discussions on incorporating the prepackaged instruction and standardizing course delivery was the hypothesis that not just more uniform practices, but better modeling practices demonstrated by student work, would be an outcome. With less time spent in lab on teaching students which buttons to click, more time could be spent on demonstrations and discussions of how to make an effective, editable, properly constrained model.

\section{The Choice of Precision LMS}

There are a variety of ways to effectively teach/train CAD. The use of written tutorials and books is common but the faculty did not want to require students to purchase a second text for the graphics courses - the cost of the LMS license is significantly less expensive than an additional text. The use of videos, including YouTube [1] screencasts [2], and blended approaches [3] have also been documented as potential approaches to CAD instruction, and most of these approaches had been used at one time or another by the EGT 120 faculty. It was lack of consistency, rather than the methodology that seemed to cause the problems in the subsequent courses.

Precision LMS tutorials had previously been implemented successfully at Penn State Behrend in a senior-level elective that required knowledge of surface modeling procedures, and a juniorlevel required course in advanced CAD practices. The faculty using these tutorials, including the course coordinator and department chair, were pleased with their quality and the ability to customize the PTC created content to a given course. One of the faculty volunteered to pilot test the tutorials in a section of EGT 120 that was being taught in the off semester, Spring 2015.

The course coordinator and the faculty member teaching the trial section worked together to select appropriate tutorials to match the existing curriculum in EGT 120. Because of the order of topics in the tutorials, some of the curriculum had to be reordered but there were no other significant changes in the content of the course. After the successful implementation in the pilot section, the use of the on-line tutorials was mandated to be incorporated across all sections of EGT 120 starting Fall 2015, some sections of EGT 121 in Spring 2016, and all sections of EGT 121 starting Fall 2016.

\section{Course Structure}

Aside from the introduction of the online Precision LMS tutorials and requiring uniform CAD instruction and grading practices, EGT 120 and 121 contained the same content in lectures, hand 
sketching exercises, and CAD topics as they had in previous semesters. The first course, EGT 120, begins with five weeks of sketching and theory instruction before CAD is introduced. Using the creation of revolved features and axial patterns as an example, the way the Precision LMS tutorials are incorporated in EGT 120 is as follows:

- During a 50 minute period, first a lecture is given based on assigned textbook reading and includes a general discussion of: revolved features; their relationship to sectional views; the use of diameters vs. radii; bolt circles and axis patterns and their impact on the creation of drawing views.

- The lecture is followed by selecting a sample part (Figure 1) from the textbook that requires the creation of a revolved feature and a pattern, and having students write and sketch the modeling strategy they would choose to create the part. The strategies are collected, some of them are chosen for discussion, followed by a short Creo demo that walks step by step through creating the model of the sample figure. The model is already finished, but the features are shown and discussed one at a time as shown in Figure 2, steps A thru D, with each feature's modeling strategy being the focus of the discussion, not how specifically to draw the profiles, locate the holes, and so on. All example problems are from the Bertoline [4] text.

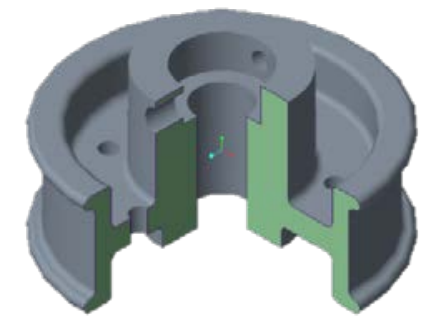

Figure 1 - Lecture Creo demo completed example

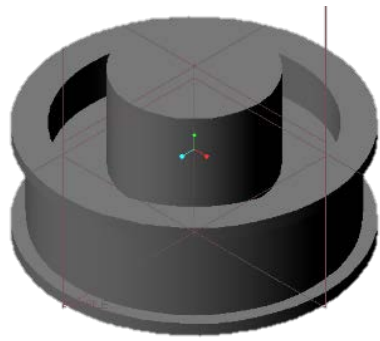

(A)

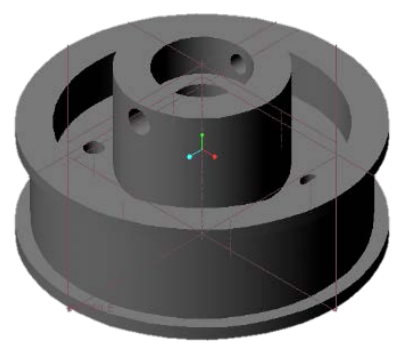

(C)

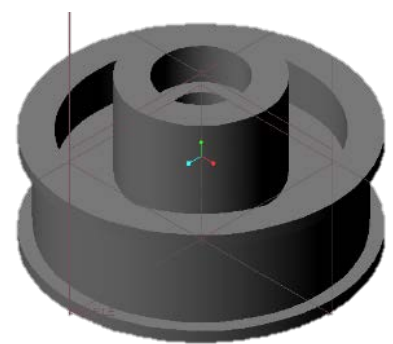

(B)

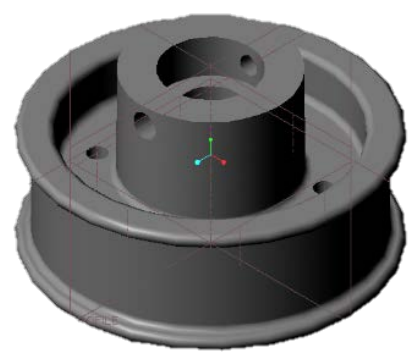

(D)

Figure 2 - Lecture Creo demo step-by-step example 
- Prior to the lecture, a Precision LMS unit had been assigned that addressed concepts, theory, and step by step practical examples on the creation of revolved features and patterns in Creo, and it was to be completed outside of class before lecture. The tutorials include videos and step-by-step instructions with detailed explanations as shown in Figures 3 and 4.

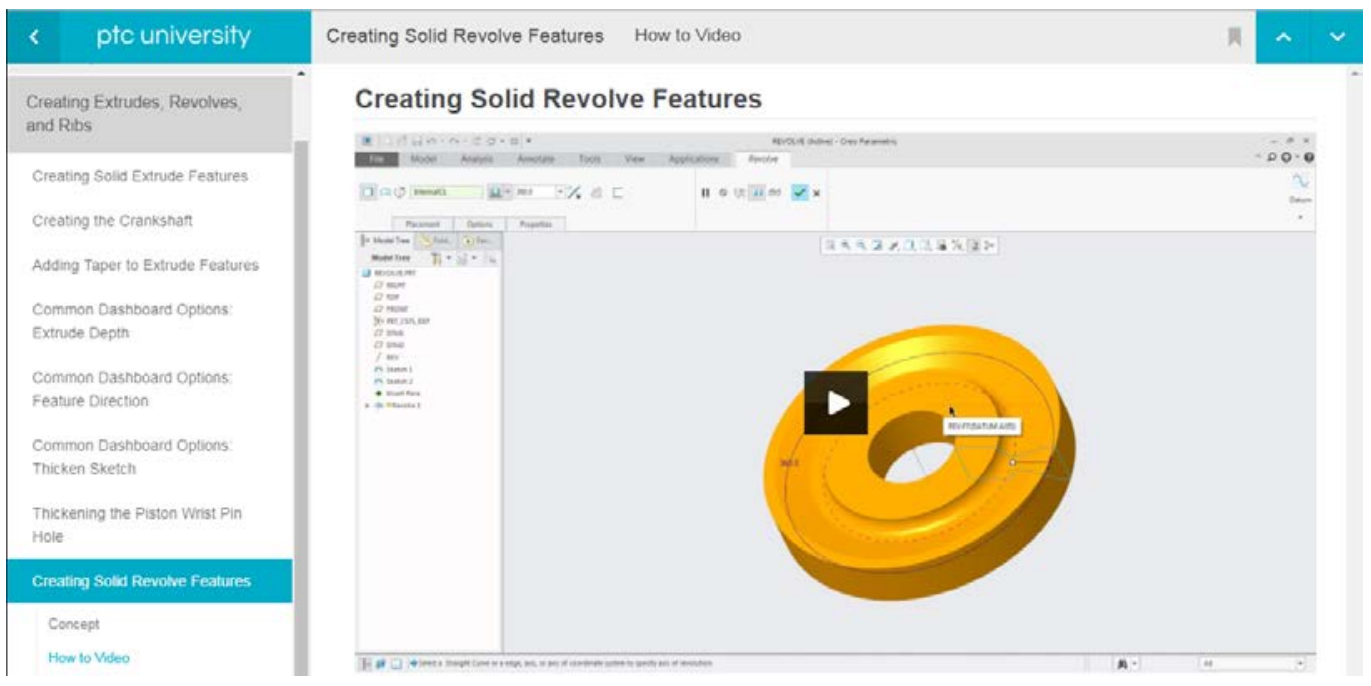

Figure 3 - Precision LMS lesson on creating revolved features [5]

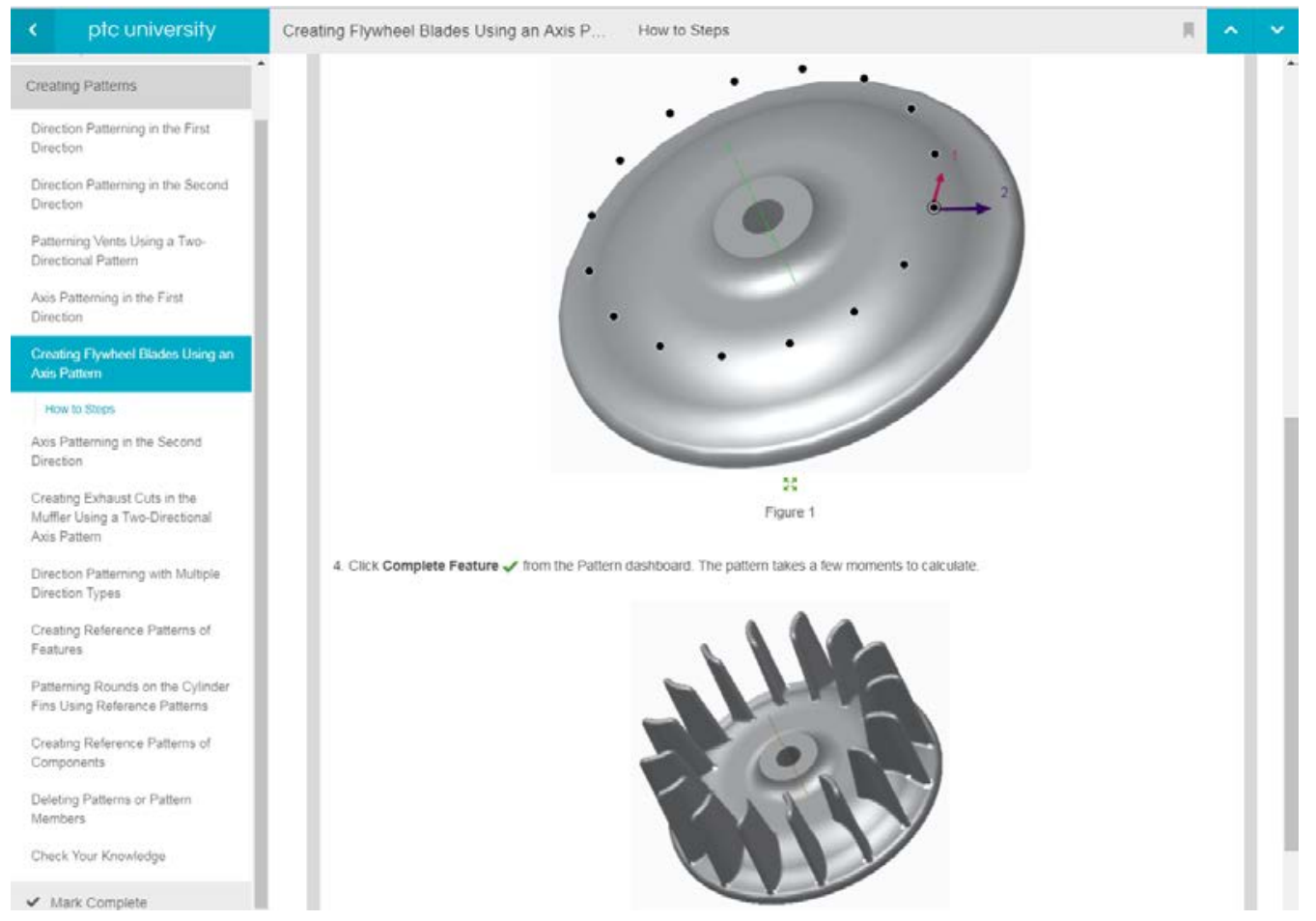

Figure 4 - Precision LMS lesson on creating axis patterns [5] 
- In the first lab period following lecture, a short 5 to 10 question on-line quiz is administered at the beginning of class to test the students' basic understanding of the information addressed both in the online tutorial and in lecture. These quizzes are administered in Canvas (the course management system used at Penn State Behrend) and automatically graded so students receive immediate feedback.

- After the quiz, there is an instructor-led demonstration of how to properly create the revolved feature in that day's assignment. Design intent and how the model should behave if certain geometric or dimensional constraints on the revolved feature are changed is discussed. Students then work on the modeling assignment which is due by the end of the 2-hour lab. All CAD files are uploaded to Canvas for grading. This first assignment focuses on creating a moderately complex profile to revolve (Figure 5) and contains few other features.

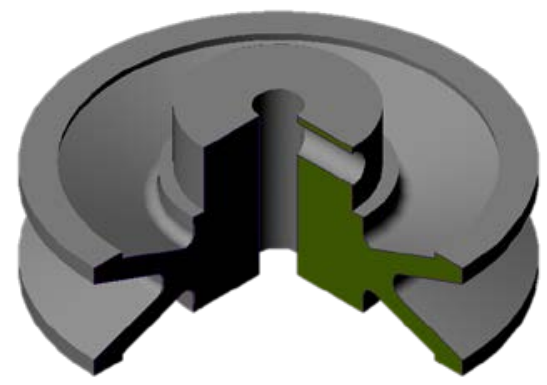

Figure 5 - Example classwork assignment

- There is a homework assignment to be completed outside of lab time that involves a simpler revolved object than the classwork, but it also includes other features that must be patterned using techniques previously demonstrated in lecture and in the Precision LMS tutorials (Figure 6). The homework assignment is discussed in class after it is assigned, and time is allowed for questions.

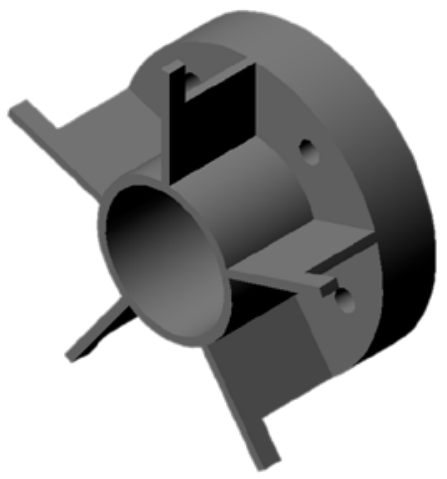

Figure 6 - Example homework assignment 
- During the second lab of the week, another CAD assignment, usually more complicated, combining revolved features and axial patterns with specific design intent (Figure 7) is given. There is also a discussion of modeling strategy, and any questions or problems the students are having with the software are addressed.

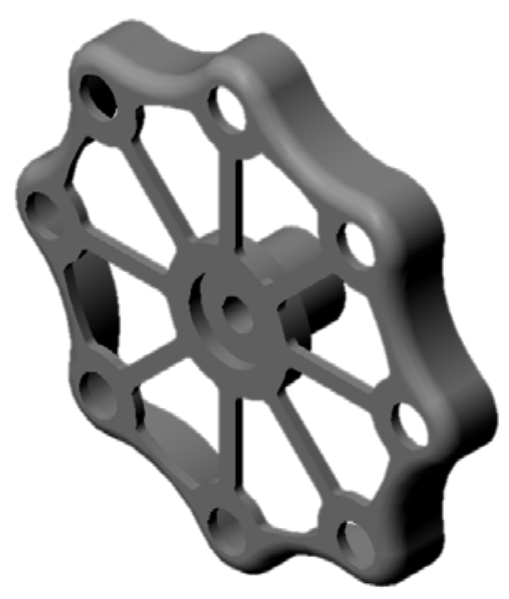

Figure 7 - Example second classwork assignment

CAD practical quizzes and exams are incorporated into the course, designed to assess students' abilities to use the commands and formats previously demonstrated with classwork and homework assignments. Students are not allowed to access the tutorials or any other online information during these quizzes and exams. They are, however, allowed to use any handwritten notes they may have with them. Figures 8 A, B, and C show models that have been used as inclass quizzes to assess the students' ability to apply their knowledge of revolutions and axial patterns by making a Creo model.

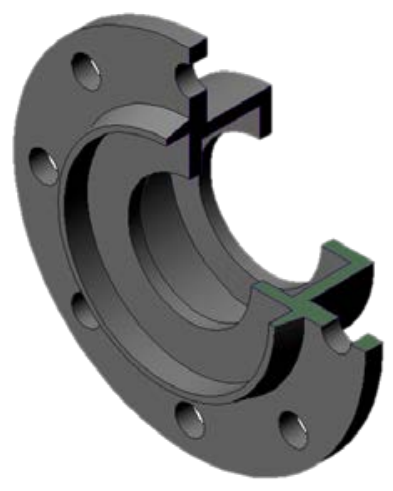

(A)

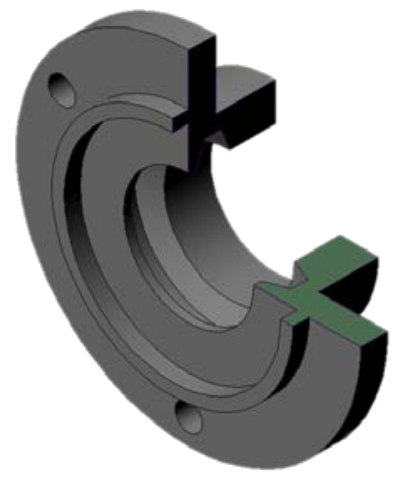

(B)

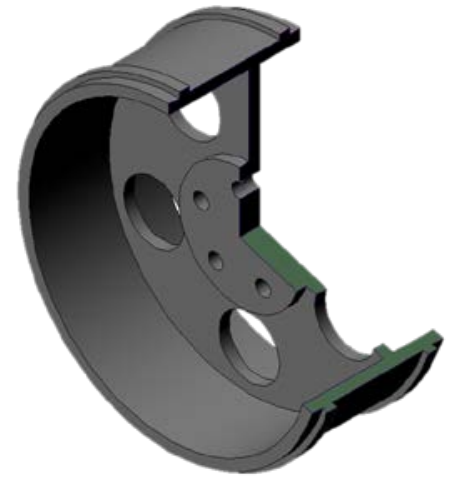

(C)

Figure 8 - Example in-class CAD quizzes

As part of the process to improve uniformity in practice, a grading rubric for each different type of CAD assignment was developed. These rubrics are to help standardize grading and are also intended to aid in students' understanding of what the focus of a given CAD assignment is. The basic types of assignments included a model (.prt file only), a model with a drawing (.prt and 
.drw files), and an assembly (.asm) with or without drawings of the individual parts and/or the assembly. Figure 9 is an example of a rubric used to grade an assignment that only required the creation of a model. These rubrics are posted on Canvas and students can always see the rubric associated with any given assignment.

\begin{tabular}{|c|c|c|c|c|c|}
\hline Criteria & \multicolumn{4}{|c|}{ Ratings } & \multirow{2}{*}{$\begin{array}{c}\text { Pts } \\
2.0 \mathrm{pts}\end{array}$} \\
\hline $\begin{array}{l}\text { Dimensions/constraints - errors include } \\
\text { but are not limited to: incorrect } \\
\text { dimension type, size, or location; weak } \\
\text { and/or incorrect constraints }\end{array}$ & $\begin{array}{l}2.0 \mathrm{pts} \\
\text { All } \\
\text { correct }\end{array}$ & $\begin{array}{l}1.0 \mathrm{pts} \\
1 \text { error }\end{array}$ & $\begin{array}{l}0.5 \mathrm{pts} \\
\text { Any weak } \\
\text { constraint }\end{array}$ & $\begin{array}{l}0.0 \text { pts } \\
>1 \text { error } \\
\text { or weak } \\
\text { constraint }\end{array}$ & \\
\hline File name includes student's name & \multicolumn{2}{|l|}{$\begin{array}{l}1.0 \mathrm{pts} \\
\text { Correct }\end{array}$} & \multicolumn{2}{|l|}{$\begin{array}{l}0.0 \text { pts } \\
\text { Incorrect }\end{array}$} & $1.0 \mathrm{pts}$ \\
\hline Feature names & \multicolumn{3}{|c|}{$\begin{array}{l}1.0 \mathrm{pts} \\
\text { All features correctly named }\end{array}$} & $\begin{array}{l}0.0 \mathrm{pts} \\
\text { Any error }\end{array}$ & $1.0 \mathrm{pts}$ \\
\hline Orientation & \multicolumn{2}{|l|}{$\begin{array}{l}1.0 \mathrm{pts} \\
\text { Correct }\end{array}$} & \multicolumn{2}{|l|}{$\begin{array}{l}0.0 \mathrm{pts} \\
\text { Incorrect }\end{array}$} & $1.0 \mathrm{pts}$ \\
\hline Units & \multicolumn{2}{|l|}{$\begin{array}{l}1.0 \mathrm{pts} \\
\text { Correct }\end{array}$} & \multicolumn{2}{|l|}{$\begin{array}{l}0.0 \text { pts } \\
\text { Incorrect }\end{array}$} & $1.0 \mathrm{pts}$ \\
\hline Unnecessary datums or features & \multicolumn{2}{|c|}{$\begin{array}{l}1.0 \mathrm{pts} \\
\text { No unnecessary } \\
\text { features or datums }\end{array}$} & \multicolumn{2}{|c|}{$\begin{array}{l}0.0 \text { pts } \\
\text { Any unnecessary } \\
\text { feature or datum }\end{array}$} & $1.0 \mathrm{pts}$ \\
\hline $\begin{array}{l}\text { Incorrect modeling techniques including } \\
\text { but not limited to: incorrect geometry, } \\
\text { missing features, incorrect depth of } \\
\text { holes or extrusions, incorrect feature } \\
\text { creation order, etc. - refer to model or } \\
\text { graded drawing for specific information }\end{array}$ & $\begin{array}{l}3.0 \mathrm{pts} \\
\text { Correct }\end{array}$ & \multicolumn{2}{|c|}{$\begin{array}{l}1.5 \mathrm{pts} \\
1 \text { or } 2 \text { errors }\end{array}$} & $\begin{array}{l}0.0 \text { pts } \\
>2 \text { errors }\end{array}$ & $3.0 \mathrm{pts}$ \\
\hline
\end{tabular}

Figure 9 - Example classwork grading rubric

\section{Outcomes and future plans}

To assess whether the tutorials and other changes to ensure standardization made a difference in the creation of effective CAD models, the grades on final projects in the courses that used the LMS were compared to those from semesters where the LMS was not implemented. The reason for choosing the final project to assess CAD skills is that the final projects consist of modeling 10-12 individual parts of varying difficulty, building an assembly with certain constraints, creating dimensioned multiview drawings of non-standard parts, and an assembly drawing with bill of materials and balloons. These projects contain elements of all the major theory topics 
covered in class, and require students to use all, or nearly all, of the CAD techniques they have learned during the semester such as; extrusions, revolutions, holes, patterns, sweeps, assemblies, and detail drawing creation. The final projects were different each semester but of similar difficulty. An example (Figure 10) of an exploded assembly drawing with a bill of materials (A), and one page of detail drawings (B) from a final project is shown. The assignment is from the Bertoline [4] text. All final projects in the study were graded with the same rubric. Multiview drawings of individual parts, the individual part models, and the assembly model and its drawings are each worth approximately $25 \%$ of the final project grade. The last $25 \%$ of the grade is for using course-specific model, assembly and drawing templates correctly and meeting formatting requirements.

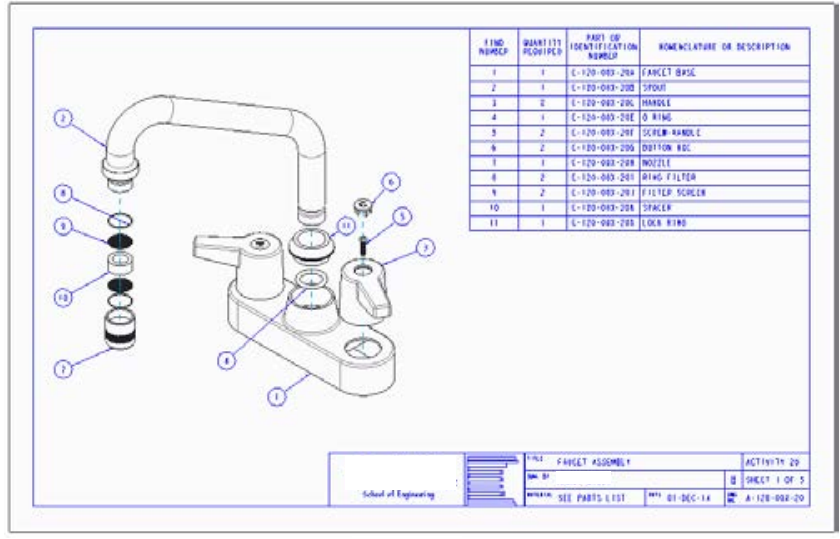

(A)

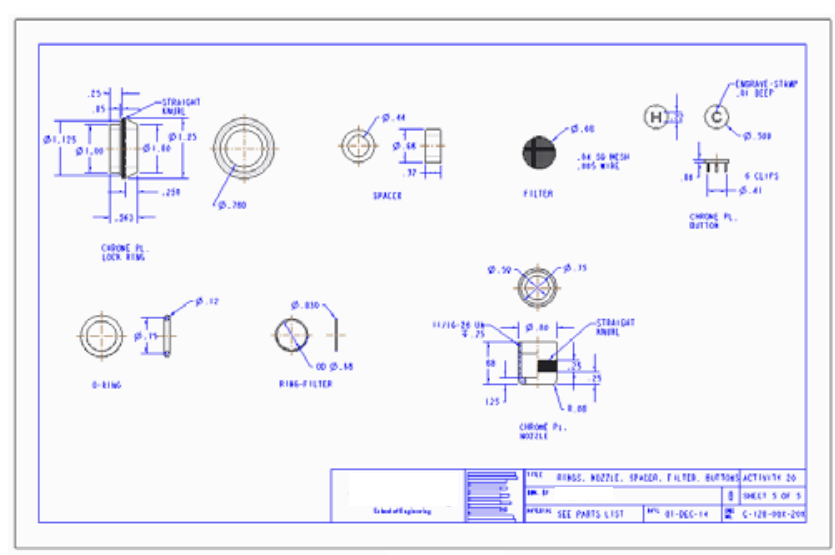

(B)

Figure 10 - EGT 120 final project example drawings

There was a statistically significant p.003 difference (Table 1) in scores on the final project, with the semesters using the LMS being higher than those that did not, $82.21 \%$ versus $85.58 \%$. There were two semesters of data from EGT 120 students not using Precision LMS, Fall 2013 and 2014, and three semesters of data from students using it, Fall 2015, 2016, and 2017. At first it was considered that the data from students using the LMS may be skewed because of a significant shift in student population during one of the semesters analyzed. Due to a local industry's layoffs, over a third of the EGT 120 students in Fall 2016 were adult students taking courses as part of the Trade Adjustment Act program [6]. Most of these adult students had significant prior experience with CAD, drafting, and manufacturing processes when compared to their typical freshman classmates. When the scores from the semesters without the adult student population, Fall 2015 and 2017, were compared to those from the semester with the large number of adult students, Fall 2016, there was no significant difference between the groups.

\begin{tabular}{|c|c|c|c|c|}
\hline \multicolumn{5}{|c|}{ T-test } \\
\hline & $\mathrm{N}$ & Mean & Std dev & P-Value \\
\hline Final Project Grade & \multicolumn{5}{|c|}{} \\
\hline \multirow{2}{*}{$\begin{array}{c}\text { Without LMS } \\
\text { With LMS }\end{array}$} & 165 & 82.21 & 10.95 & \\
\cline { 2 - 4 } 0 & 213 & 85.58 & 10.49 & 0.003 \\
\hline
\end{tabular}

Table 1 - final project grade comparison 
All instructors of EGT 120 are now using the on-line tutorials in their courses. The significant improvement in final project scores indicates that the more uniform instruction of CAD techniques and standardized grading procedures resulted in overall better CAD skills demonstrated by the students. That is not to say it is solely the result of the Precision LMS tutorials' content, because similar results likely could have been obtained by the mandatory use of a textbook or step-by-step tutorials created by the course coordinator and other faculty, along with still requiring that all faculty teaching the course do the same/similar demos, use the same grading schemes, and so on. However, there are several benefits to using Precision LMS or other similar quality prepackaged instruction. One of them is that the significant amount of time and effort required to create and update instructional materials does not fall directly on individual instructors. In the past, some instructors would spend weeks writing and revising self-created tutorials tailored to a specific course. Several faculty did this for multiple courses in their 4/4 teaching load. All the course coordinator needs to do now is build new lessons in Precision LMS that cover the required course topics and this, combined with the use of standard rubrics and so on, results in more equitable instructional delivery to the students.

Another major benefit to the students is as long as they have an active license, they can access any of the topics available on Precision LMS, not just the ones that have been packaged and assigned to them specifically for EGT 120/121. The tutorials are available to help with questions 24/7 unlike their professors, classmates, and tutors, and they provide consistent instruction that does not conflict with the modeling methodologies preferred across the curriculum by the engineering and engineering technology programs at Penn State Behrend. Recent feedback indicates the changes also better meet the expectations of some of our industrial partners who hire Behrend students as interns to do CAD work. The cost for students who remain enrolled in their engineering majors breaks down to less than \$20 per course because LMS access is also required in upper level courses that have a CAD component, not solely EGT 120/121.

During the pilot semester and the following semesters of full implementation, there were few problems with the implementation and use of the tutorials. In general, what problems did exist were primarily along the lines of students not following instructions on how to purchase their license and thus not being prepared for class, or not completing the assigned tutorials before class and not being able to fully understand the in-class work. There is a way in Precision LMS to track access to content, but that was not used regularly by faculty because it requires administrator access and some faculty, especially the adjuncts, did not want or need this full access. One option that was tried and quickly discarded was having students print the final page of the tutorials to show they had completed them and marked them as finished, but this was too easily spoofed by having a classmate print two or more copies of their final page.

The short in-lab true/false and multiple-choice quizzes mentioned previously were written to be closely aligned with the Precision LMS content and lecture content, and they were implemented instead of other methods of tracking student access to the tutorials. They have proven an effective way to assess whether students were actually completing the tutorials and answering the embedded questions. These quizzes are automatically graded so after they are written and uploaded to Canvas by the course coordinator, there is little added work load for faculty except to make the quizzes available and set the time limits. As far as assigning the tutorials, it was 
found to be less complicated to have one faculty member be the administrator of content for all course sections and set up the online tutorials, add students to the course groups, and make assignments of individual tutorials to the groups.

A prerequisite quiz was pilot tested in certain sections of EGT 121 beginning in the Spring 2017 semester, but results should only be considered anecdotal at this point. Although students are required to have passed EGT 120 or its equivalent to enroll in EGT 121, at the time of administering the quiz pilot, students were not asked if they had taken an EGT 120 course section that incorporated the Precision LMS or not. Historical data indicates that only approximately 70\% of the students enrolled in EGT 120 enroll in EGT 121 the immediately following semester. Therefore, the majority of students taking the prerequisite quiz would likely have had experience with the Precision LMS, but not all. The following data is from 99 students who took the EGT 121 prerequisite quiz. Of that group, 77 earned a passing grade of over $70 \%$. The average grade of those not passing was $60 \%$. Of the 22 students not passing, 15 only took the quiz once when they were allowed to retake it up to 4 times to improve their grade. Of the 77 that passed, 19 took it once, 15 took it twice, 23 took it three times and 20 took it four times. A passing score was not enforced, meaning that students were not required to take the quiz again if they did not pass the first time. There is no data to compare these initial results to, and the quiz questions are being analyzed to determine their discrimination indices and other factors of validity and reliability. After discussion amongst the faculty who teach EGT 121, a passing score of $70 \%$ will be enforced in future semesters - this option has been added to the quiz in Canvas. Results of this quiz will be collected from multiple semesters of EGT 121 and assessed to see if it is actually measuring retention of knowledge from EGT 120, and if the scores on the quiz have any relationship to success in the course.

\section{References}

[1] R. Cozzens, "YouTube: An Effective CAD Training Resource," in Proceedings of the 2012 ASEE Annual Conference and Exposition, San Antonio, Texas. https://peer.asee.org/22259

[2] D. Zhang, X. Peng, B. Yalvac, D. Eseryel, U. Nadeem, A. Islam, T. F. Eyupoglu, and T. Yuan, "Using Peer-Generated Screencasts in Teaching Computer-Aided Design," in Proceedings of the 2016 ASEE Annual Conference and Exposition, New Orleans, Louisiana. 10.18260/p.27159

[3] D. M. Yip-Hoi, and J. G. Welch, "Enhancing a Blended Learning Approach to CAD Instruction Using Lean Manufacturing Principles," in Proceedings of the 2015 ASEE Annual Conference and Exposition, Seattle, Washington. 10.18260/p.23994

[4] G. R. Bertoline, E. N. Wiebe, N. W. Hartman, and W. A. Ross, Fundamentals of graphics

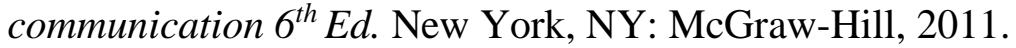

[5] PTC University Precision LMS, http://precisionlms.ptc.com [Accessed 17, October, 2017].

[6] United States Department of Labor. Trade Adjustment Assistance Program, https://www.doleta.gov/Tradeact/ [Accessed 17, October, 2017]. 